\title{
Dose dependency of the effect of ornithine $\alpha$-ketoglutarate on tissue glutamine concentrations and hypercatabolic response in endotoxaemic rats
}

\author{
Pascal Pernet ${ }^{1,2} *$, Colette Coudray-Lucas ${ }^{1,2}$, Christina Schneid ${ }^{2}$, Alain Jardel ${ }^{3}$ and Luc Cynober ${ }^{2,4}$ \\ ${ }^{1}$ Service de Biochimie A, Hôpital Saint-Antoine, AP-HP, Paris, France \\ ${ }^{2}$ Laboratoire de Biologie de la Nutrition EA 2498, Faculté de Pharmacie, Paris, France \\ ${ }^{3}$ Laboratoire de Physiologie, Faculté de Pharmacie, Angers, France \\ ${ }^{4}$ Service de Biochimie A, Hôtel-Dieu, AP-HP, Paris, France
}

(Received 2 February 2004 - Revised 18 June 2004 - Accepted 1 July 2004)

\begin{abstract}
The optimal dosage of ornithine $\alpha$-ketoglutarate (OKG) for repleting tissue glutamine (Gln) concentrations and maintaining $\mathrm{N}$ homeostasis after injury is unknown. We set out to perform 'dose-ranging' of OKG supplementation after an endotoxaemic challenge. Sixty-one male Wistar rats were injected with $3 \mathrm{mg}$ lipopolysaccharide (LPS) from Escherichia coli/kg ( $n$ 50) or saline vehicle (9 $\mathrm{g} \mathrm{NaCl} / 1$; controls $n$ 11). After a $24 \mathrm{~h}$ fast, survivors were fed by gavage for $48 \mathrm{~h}$ with a polymeric standard diet $(879 \mathrm{~kJ} / \mathrm{kg}$ per d and $1.18 \mathrm{~g} \mathrm{~N} / \mathrm{kg}$ per d) supplemented with non-essential amino acids (control, $n$ 11; LPS-OKG-0.0, $n$ 9), or with $0.5 \mathrm{~g} \mathrm{OKG/kg} \mathrm{per} \mathrm{d} \mathrm{(LPS-OKG-0.5,} n$ 12), 1.5 $\mathrm{OKG} / \mathrm{kg}$ per $\mathrm{d}$ (LPS-OKG-1.5, $n$ 11) or $4.5 \mathrm{~g} \mathrm{OKG} / \mathrm{kg}$ per $\mathrm{d}$ (LPS-OKG-4.5, $n$ 10). The diets for all groups were made isonitrogenous with the LPS-OKG-4.5 diet by adding an appropriate amount of non-essential amino acids. Rats were killed on day 3 for blood and tissue sampling (muscle, jejunum mucosa, liver). Urine was collected daily for 3-methylhistidine and total $\mathrm{N}$ assays. The OKG dose was correlated with Gln concentrations in every tissue and with cumulative N balance (Spearman test, $P<0 \cdot 01$ ). 3-Methylhistidine excretion was increased in endotoxaemic groups compared with controls (ANOVA, $P<0 \cdot 05$ ) except in the LPS-OKG-4.5 group. Only the LPS-OKG-4.5 group achieved a positive post-injury $\mathrm{N}$ balance $(t$ test, $P<0 \cdot 05)$. In conclusion, OKG exerted a dose-dependent effect on tissue Gln concentration and $\mathrm{N}$ balance, but only the highest dosage counteracted myofibrillar hypercatabolism and caused a positive $\mathrm{N}$ balance.
\end{abstract}

Ornithine $\alpha$-ketoglutarate: Glutamine: Endotoxaemia: Injury

Pharmaconutrition denotes the use of metabolic regulating substances to correct functional and metabolic disorders induced by injury (Cynober, 1995; De Bandt \& Cynober, 1998). Ornithine $\alpha$-ketoglutarate (OKG) has been used for this purpose in various pathological situations (Cynober, 2004). OKG is a salt, stable in solution, which can be given by oral, enteral or parenteral routes; it is formed of one molecule of $\alpha$-ketoglutarate and two of ornithine (Orn). This pharmaconutrient is characterized by both anticatabolic and anabolic activities (De Bandt \& Cynober, 1998; Cynober, 2004); it acts as an efficient immunomodulator (Roch-Arveiller et al. 1996; Robinson et al. 1999; Moinard et al. 2002) and as a key promoter of wound healing and tissue repair (Coudray-Lucas et al. 2000). OKG supplementation results in an improvement of nutritional and biochemical status and of the clinical outcome of injured patients (De Bandt \& Cynober, 1998; Cynober, 2004). OKG action is complex, involving its components, Orn and $\alpha$-keto-glutarate, and its metabolites generated in vivo, namely glutamine (Gln), arginine (Arg), proline (Pro) and polyamines
(Le Boucher \& Cynober, 1998). Moreover, a specific interaction between the two components is involved in the effects of OKG (Cynober et al. 1990; Le Boucher \& Cynober, 1998), leading to an increase in Gln pools in vivo that is not observed when Orn is replaced by Arg (Le Boucher et al. 1997). Besides clinical trials (for reviews, see Cynober, 1999; Cardenas et al. 2002; Blondé-Cynober et al. 2003), numerous experimental studies have found beneficial metabolic effects of OKG in experimental models of injury, such as burns (Vaubourdolle et al. 1991), trauma (Jeevanandam et al. 1992), cancer (Le Bricon et al. 1994), endotoxaemia (Lasnier et al. 1996) and intestinal ischaemia (Duranton et al. 1998). These studies used different doses from 0.5 to $5.0 \mathrm{~g} / \mathrm{kg}$ per d. However, there was no strong rationale for the doses of OKG used in most of these experiments. 'Dose-ranging' has already been carried out in human subjects (Le Bricon et al. 1997; De Bandt et al. 1998). However, limited information was obtained, because the effects of OKG were evaluated non-invasively only, in particular by measuring plasma OKG metabolites.

\footnotetext{
Abbreviations: Arg, arginine; Gln, glutamine; LPS, lipopolysaccharide; OKG, ornithine $\alpha$-ketoglutarate; Orn, ornithine; Pro, proline.

* Corresponding author: Dr Pascal Pernet, fax + 331492820 77, email pascal.pernet@sat.ap-hop-paris.fr
} 
In the present study, the adequate dosage of OKG to be used was determined on the basis that the dosage should reproduce the main beneficial effects of OKG on hypercatabolic states. We focused on the tissue level to investigate OKG action on tissues according to dose more closely. For this purpose, we administered different doses of OKG covering the range of OKG doses previously used in experimental models; we used a severe endotoxaemia model as a reproducible model of hypercatabolism (Fink \& Heard, 1990).

\section{Materials and methods}

\section{Animals}

Sixty-one male Wistar rats (Centre d'Élevage René Janvier, Saint-Denis-Les-Laval, France) 8 weeks old and weighing 180-200 g were used. They were housed individually in stainless-steel wire-bottomed metabolism cages with a reversed $12 \mathrm{~h}$ light-dark cycle (lights off 08.00 to 20.00 hours) in a thermostatically controlled room $\left(22^{\circ} \mathrm{C}\right)$. They were acclimatized to standard laboratory conditions for $5 \mathrm{~d}$ with free access to water and rat chow (UAR A03; Usine d'Alimentation Rationnelle, Epinay-sur-Orge, France) before the beginning of the experiments. Animal care complied with the rules of the Saint-Antoine Hospital animal facility. Three of the investigators (L. C., A. J. and C. C. -L.) are authorized by the French Ministry of Agriculture to use this experimental model.

\section{Study design}

After acclimatization (day 0), rats were allocated in two experimental groups: a lipopolysaccharide (LPS)-injected group and a control group (Table 1). Endotoxin from Escherichia coli 0127:B8 dissolved in saline $(9 \mathrm{~g} \mathrm{NaCl} / \mathrm{l}$; $10 \mathrm{ml} / \mathrm{kg}$ body weight) was injected intraperitoneally at a dose of $3 \mathrm{mg} / \mathrm{kg}$ in the LPS-treated group, while the control rats received only saline vehicle. After injection the rats were fasted for $24 \mathrm{~h}$ (from day 0 to day 1) with free access to water. On day 1, survivors of the LPS group were randomized into four subgroups defined by the daily dose of OKG (Chiesi SA, Courbevoie, France) mixed with their enteral nutrition (see later). Rats were enterally fed for $48 \mathrm{~h}$ (from day 1 to day 3 ) in three daily gavages $(08.00,13.00$ and 18.00 hours) using a standard polymeric diet (Osmolite ${ }^{\circledR}$; Abbott, Rungis, France) as previously described (Vaubourdolle et al. 1991; Lasnier et al. 1996). Enteral nutrition supplied $879 \mathrm{~kJ} / \mathrm{kg}$ per d $(1.18 \mathrm{~g} \mathrm{~N} /$ $\mathrm{kg}$ per d) with no additional daily OKG dose (control group and LPS-OKG-0.0 group) or an additional dose of 0.5 (LPS-OKG-0.5 group), 1.5 (LPS-OKG-1.5 group) or 4.5 (LPS-OKG-4.5 group) g OKG/kg per $\mathrm{d}$. The diets for all groups were made isonitrogenous with the LPS-OKG-4.5 group by adding an appropriate amount (see Table 1) of a mixture of non-essential amino acids (glycine, alanine and serine, each amino acid supplying one-third of the extra N needed; Sigma, Saint-Louis, MO, USA). OKG and non-essential amino acids were dissolved in the enteral nutrition solution. The rats were killed by decapitation on day 3 ( $6 \mathrm{~h}$ after the last gavage).

Urine was collected daily from day 0 to day 3 . Sodium ethylmercurithiosalicylate solution $(1 \mathrm{mg} / 1,50 \mu \mathrm{l}$; Prolabo, Paris, France) was added to each collection container to prevent bacterial growth. Samples were then stored at $-20^{\circ} \mathrm{C}$ until determination of $\mathrm{N}$ and 3-methylhistidine excretion. At killing, blood was collected on heparinate from the neck. Blood was centrifuged (10 min, $3500 \mathrm{~g}$ ). Plasma was then deproteinized with sulfosalicylic acid $(50 \mathrm{mg} / \mathrm{ml})$ and centrifuged. The supernatant fractions were stored at $-80^{\circ} \mathrm{C}$. Liver and anterior tibialis muscles were promptly removed, weighed and frozen in liquid $\mathrm{N}_{2}$, and then stored at $-80^{\circ} \mathrm{C}$. A $100 \mathrm{~mm}$ segment of jejunum located $100 \mathrm{~mm}$ from the pylorus was removed, washed with $4^{\circ} \mathrm{C}$ saline $(9 \mathrm{~g} \mathrm{NaCl} / \mathrm{l})$, weighed and then opened longitudinally on a glass board placed on ice. The jejunum mucosa was scraped off and weighed, frozen in liquid $\mathrm{N}_{2}$ and stored at $-80^{\circ} \mathrm{C}$ until analysis.

\section{Measurements}

Urinary nitrogen. Total urinary $\mathrm{N}$ levels were measured by pyrochemiluminescence on an Antek $5000 \mathrm{~N}$ (Antek Instrument, Düsseldorf, Germany). $\mathrm{N}$ balance was calculated for each day ( $\mathrm{N}$ intake - urinary $\mathrm{N}$ excretion) and cumulated for the $2 \mathrm{~d}$ of the re-nutrition period.

Urinary 3-methylhistidine. In the rat, 3-methylhistidine is chiefly excreted in urine in acetylated form. Samples

Table 1. Definition of the five experimental groups according to the presence or absence of endotoxaemia and the dose of ornithine $\alpha$-ketoglutarate supplementation

\begin{tabular}{|c|c|c|c|c|c|c|}
\hline Group... & $\begin{array}{l}\text { Control } \\
(n 11)\end{array}$ & $\begin{array}{l}\text { LPS } \\
(n 50)\end{array}$ & $\begin{array}{c}\text { LPS-OKG-0.0 } \\
(n 9)\end{array}$ & $\begin{array}{l}\text { LPS-OKG-0.5 } \\
(n 12)\end{array}$ & $\begin{array}{c}\text { LPS-OKG-1.5 } \\
(n 11)\end{array}$ & $\begin{array}{c}\text { LPS-OKG-4.5 } \\
(n 10)\end{array}$ \\
\hline \multicolumn{7}{|c|}{ Day 0 to day 1 : injections and fasting } \\
\hline Endotoxin* & - & + & & & & \\
\hline Saline† & + & - & & & & \\
\hline \multicolumn{7}{|c|}{ Day 1 to day 3 : nutrition } \\
\hline Osmolite ${ }^{\mathbb{Q}} \neq$ & + & & + & + & + & + \\
\hline OKG (g/kg per d) & 0.0 & & 0.0 & 0.5 & 1.5 & 4.5 \\
\hline NEAA $(\mathrm{g} / \mathrm{kg}$ per $\mathrm{d})$ & $3 \cdot 8$ & & 3.8 & 3.4 & 2.5 & 0.0 \\
\hline
\end{tabular}

LPS, lipopolysaccharide; OKG, ornithine ( $\alpha$-ketoglutarate); NEAA, non-essential amino acids. + and - , presence and absence of administration of the stated substance.

*The endotoxin was LPS from Escherichia coli 027:B8 (3 mg/kg).

† $9 \mathrm{~g} \mathrm{NaCl} / \mathrm{l}, 90 \mathrm{mg} / \mathrm{kg}$.

$\ddagger$ Abbott, Rungis, France; $879 \mathrm{~kJ} / \mathrm{kg}$ perd, $1.18 \mathrm{~g} \mathrm{~N} / \mathrm{kg}$ per d. 
were therefore hydrolysed with $6 \mathrm{M}-\mathrm{HCl}$ at $80^{\circ} \mathrm{C}$ for $24 \mathrm{~h}$ before quantification by ion-exchange chromatography and ninhydrin detection using a model 6300 Beckman analyser (Beckman, Palo Alto, CA, USA).

Plasma and tissue amino acids. Plasma was separated by centrifugation, deproteinized with sulfosalicylic acid $(50 \mathrm{mg} / \mathrm{l})$ and stored at $-80^{\circ} \mathrm{C}$ until amino acid analysis. Anterior tibialis, liver and jejunum mucosa were homogenized in TCA $(100 \mathrm{ml} / \mathrm{l})$ containing $0.5 \mathrm{mmol}$ EDTA/l. After centrifugation, the supernatant fractions were stored at $-80^{\circ} \mathrm{C}$ until amino acid analysis. Amino acid (Arg, Gln, Orn, Pro) concentrations in plasma and supernatant fractions were measured by ion-exchange chromatography on a Beckman 6300 analyser (Beckman).

\section{Statistical analysis}

Results are expressed as mean values with their standard errors. For organ weights, $\mathrm{N}$ balance, 3-methyhistidine excretion and plasma amino acid concentrations, comparisons between five groups were made using one-way ANOVA. When an overall significant difference among the five groups was found, the Newman-Keuls test was performed to determine which groups differed. In endotoxaemic groups, correlations between OKG dose and $\mathrm{N}$ balance, 3-methylhistidine excretion and plasma amino acid concentrations were sought using linear regression (Spearman test). A one-sample $t$ test compared the mean of $\mathrm{N}$ balance against a hypothetical mean of 0 (i.e. the hypothesis that average balance does not differ from zero). Statistical analyses were done using Graphpad Prism (version 3.02; GraphPad Software Inc., San Diego, CA, USA). Differences were considered significant at $P<0 \cdot 05$. Significance levels quoted were two-sided.

\section{Results}

Mortality rate

In the LPS group, eight rats $(16 \%)$ died after endotoxin injection; forty-two rats were therefore randomized for nutritional supplementation on day 1 .

\section{Nitrogen balance}

From day 0 to day $1, \mathrm{~N}$ balance in the LPS group ( -276 (SE 53) $\mathrm{mg}$ ) was statistically more negative than that in the control group $(-214$ (SE 87) mg); $P<0.05$ ). From day 1 to day 3, cumulative $\mathrm{N}$ balance was not different between groups (mg): control 53 (SE 24); LPS-OKG-0.0 0 (SE 20); LPS-OKG-0.5 9 (SE 23); LPS-OKG-1.5 22 (SE 35); LPSOKG-4.5 73 (SE 12). When the mean values of cumulative $\mathrm{N}$ balances were tested against a hypothetical mean of 0 (one-sample $t$ test), only the LPS-OKG-4.5 group showed a positive balance $(P<0 \cdot 05)$. Interestingly, a statistical correlation between $\mathrm{OKG}$ dose and cumulative $\mathrm{N}$ balance in endotoxaemic groups $(y=16 \cdot 2 x-0.3, r 0.99)$ was observed (see Fig. 1).

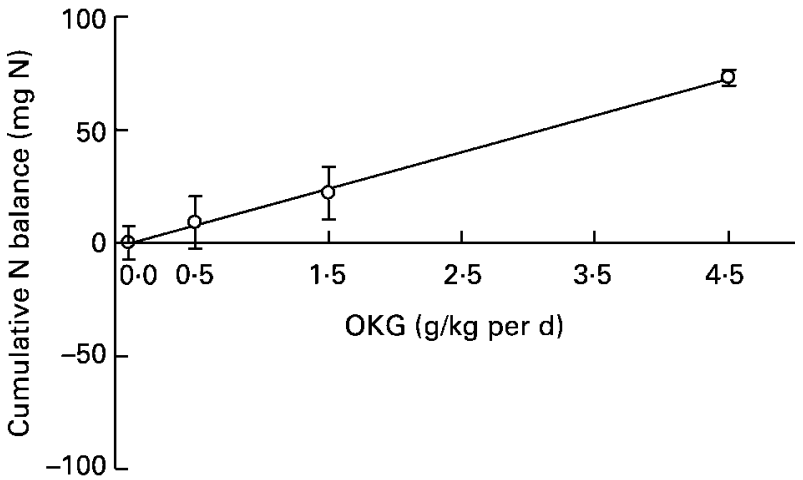

Fig. 1. Linear regression between ornithine $\alpha$-ketoglutarate (OKG) dose and day 1 to day 3 cumulative nitrogen balance. For details of diets and procedures, see Table 1 and pp. 628-629. Values are mean with their standard errors shown by vertical bars. $y=16 \cdot 2 x-$ $0.3 ; r 0.99, P<0.001$ (Spearman rank test).

\section{3-Methylhistidine excretion}

Results are reported in Fig. 2. Cumulative 3-methylhistidine excretion was statistically higher in the LPS-OKG$0 \cdot 0$, LPS-OKG-0.5 and LPS-OKG-1.5 groups than in the control group, whereas the LPS-OKG-4.5 group was not different from controls. No statistical correlation was found between OKG dose and 3-methylhistidine excretion in the endotoxaemic groups.

\section{Organ weights}

The weights of jejunum and anterior tibialis at killing (results not shown) were not statistically different between groups. Liver weight (expressed as \% total body weight) increased in all endotoxaemic groups (LPS-OKG-0.0 4.0 (SE 0.4), LPS-OKG-1.5 4.0 (SE 0.3), LPS-OKG-1.5 4.1 (SE 0.4), LPS-OKG-4.5 4.0 (SE 0.3)) compared with the control group $(3 \cdot 6(\mathrm{SE} 0 \cdot 2))$.

\section{Plasma and tissue amino acid concentrations}

Glutamine. Results for Gln concentrations are reported in Table 2. In plasma, Gln concentrations were greater in the LPS-OKG-4.5 group than in the four other groups. In jejunum mucosa and in liver, Gln concentrations were greater in the LPS-OKG-4.5 group than in the control, LPS-OKG0.0 and LPS-OKG- 0.5 groups, and also greater in the LPSOKG-1.5 group than in the control and LPS-OKG-0.0 groups. Muscle Gln concentrations in LPS-OKG-0.0 and LPS-OKG-0.5 groups were lower than those in the control group, whereas $\mathrm{OKG}$ at 1.5 and $4.5 \mathrm{~g} / \mathrm{kg}$ per d counteracted Gln depletion.

In endotoxaemic rats, a significant positive linear relation was found between administered OKG dose and Gln concentration in plasma, anterior tibialis, liver and jejunum mucosa (Fig. 3).

Ornithine. Results are reported in Table 3. Orn concentrations in the LPS-OKG-4.5 group were significantly greater than those in the four other groups in plasma, anterior tibialis, jejunum mucosa and liver. Moreover, in endotoxaemic rats, a significant $(P<0.01)$ positive linear relation was found between administered OKG dose and 


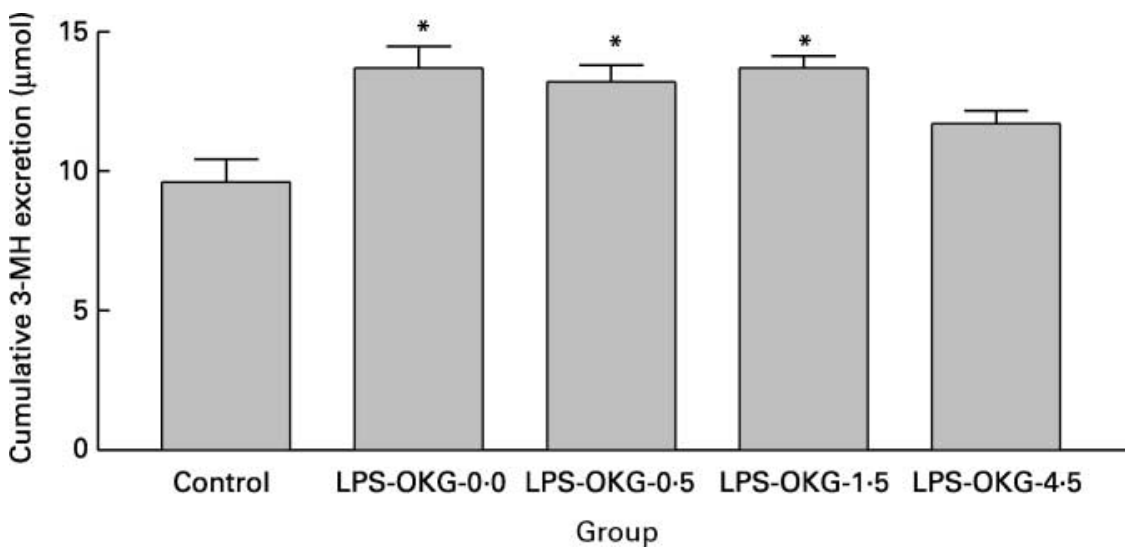

Fig. 2. Day 1 to day 3 cumulative 3-methylhistidine (3MH) urinary excretion following injury. LPS, lipopolysaccharide; OKG, $\alpha$-ketoglutarate. For definition of groups, and details of diets and procedures, see Table 1 and pp. 628-629. Values are means with their standard errors shown by vertical bars. Mean values were significantly different from that of the control group: ${ }^{\star} P<0.05$ (ANOVA followed by a Newman-

Table 2. Plasma and tissue glutamine concentrations at killing ${ }^{\star} \dagger$ (Mean values with their standard errors)

\begin{tabular}{|c|c|c|c|c|c|c|c|c|c|c|}
\hline \multirow{2}{*}{ Group... } & \multicolumn{2}{|c|}{ Control } & \multicolumn{2}{|c|}{ LPS-OKG-0.0 } & \multicolumn{2}{|c|}{ LPS-OKG-0.5 } & \multicolumn{2}{|c|}{ LPS-OKG-1.5 } & \multicolumn{2}{|c|}{ LPS-OKG-4.5 } \\
\hline & Mean & SEM & Mean & SEM & Mean & SEM & Mean & SEM & Mean & SEM \\
\hline Plasma $(\mu \mathrm{mol} / \mathrm{l})$ & $880^{a}$ & 33 & $793^{a}$ & 17 & $794^{a}$ & 33 & $864^{a}$ & 17 & $990^{\mathrm{b}}$ & 36 \\
\hline Jejunum mucosa $(\mathrm{nmol} / \mathrm{g})$ & $662^{a}$ & 52 & $632^{\mathrm{a}}$ & 64 & $672^{\mathrm{ab}}$ & 76 & $796^{\text {bc }}$ & 54 & $940^{\mathrm{C}}$ & 69 \\
\hline Liver $(\mathrm{nmol} / \mathrm{g})$ & $6362^{a}$ & 234 & $5889^{a}$ & 190 & $6336^{\mathrm{ab}}$ & 347 & $6782^{\mathrm{bc}}$ & 154 & $7382^{c}$ & 353 \\
\hline Anterior tibialis (nmol/g) & $4094^{a}$ & 184 & $3127^{b}$ & 268 & $3071^{\mathrm{b}}$ & 122 & $3397^{\mathrm{ab}}$ & 100 & $4144^{a}$ & 389 \\
\hline
\end{tabular}

LPS, lipopolysaccharide; OKG, ornithine $\alpha$-ketoglutarate.

a,b,c Mean values within a row with unlike superscript letters were significantly different $(P<0.05)$.

${ }^{*}$ For details of groups and procedures, see Table 1 and pp. 628-629.

†For each variable, when an overall significant difference among the five groups was found (one-way ANOVA), the Newman-Keuls post hoc test was performed.

Githls Rostceaptaston in plasma $(y=39 x+25 ; r$ 0.74), anterior tibialis $(y=108 x+3 ; \quad r \quad 0.74)$ and jejunum mucosa $(y=19 x+72 ; r 0 \cdot 71)$.

Proline. Results are reported in Table 4. Concentrations of Pro in the LPS-OKG-4.5 group were significantly greater in plasma and anterior tibialis than in the four other groups, and in the control and LPS-OKG-1.5 groups in the liver $(P<0 \cdot 05)$. Liver Pro concentrations in endotoxaemic groups were significantly greater than in the control group. In endotoxaemic rats, a significant $(P<0.01)$ positive linear relation was found between OKG administered dose and Pro concentrations in plasma $(y=32 x+170 ; \quad r \quad 0.72)$ and anterior tibialis $(y=77 x+266 ; r$ 0.81). No differences between groups were found for jejunum mucosa.

Arginine. Results are reported in Table 5. Arg concentrations in the control and LPS-OKG-4.5 groups were significantly greater in anterior tibialis than in the LPS-OKG-0.5 and LPS-OKG-1.5 groups $(P<0.05)$. No differences between groups were found in plasma or jejunum mucosa. Arg concentrations in liver were undetectable.

\section{Discussion}

'Dose-ranging' studies are mandatory to assess the effects of pharmaconutrients, yet very few such studies are available in the literature. To evaluate the effects of $\mathrm{OKG}$ using controlled nutrition, we had to choose an experimental model that would induce a reproducible state of injury. For this purpose, we used an endotoxaemic rat model, since endotoxaemia may be involved in the pathogenesis of sepsis and is known to induce a marked reproducible hypercatabolic state (Lasnier et al. 1996). Endotoxaemia, and caecal ligation and puncture, induce the same pattern of pro-inflammatory cytokine production ( $\mathrm{P}$ Wischmeyer, personal communication). The dose of endotoxin from $E$. coli 0127:B8 used in the present study $(3 \mathrm{mg} / \mathrm{kg})$ has been shown to induce a mortality rate of $20 \%$ in young rats (Pernet et al. 1999). These results are close to the mortality rate of $16 \%$ observed in the present experiments and confirm that this dose of LPS inflicts major injury. However, because rats are able to recover quickly from injuries, they were subsequently fasted to potentiate and prolong the effects of the endotoxaemia (Vaubourdolle et al. 1991) in order to evaluate the beneficial effects of the $2 \mathrm{~d}$ nutrition. This controlled nutrition was made isonitrogenous to avoid bias of $\mathrm{N}$ intake, and a mixture of non-essential amino acids, considered to be the most inert N source, was used as an isonitrogenous control (Chambon-Savanovitch et al. 1999). High doses of a single amino acid used as isonitrogenous control, such as glycine (Hall, 1998), may exert metabolic effects and induce bias of interpretation.

In previous experimental studies in rats, $\mathrm{OKG}$ doses ranged from 0.5 (Lasnier et al. 1996) to $5.0 \mathrm{~g} / \mathrm{kg}$ per d 
(A)

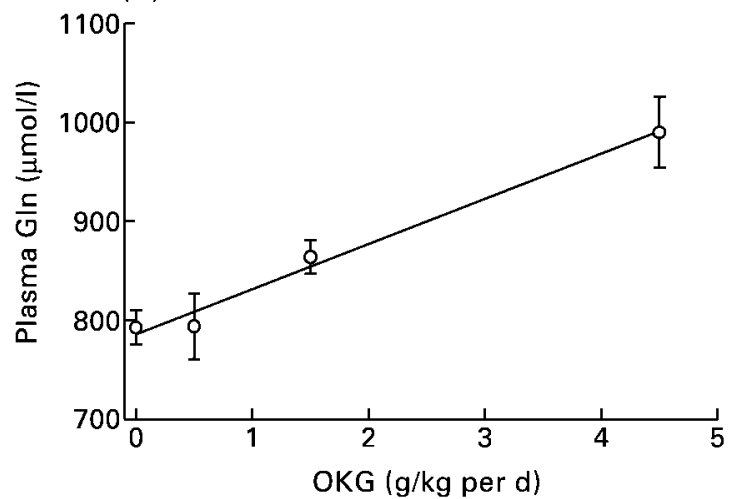

(C)

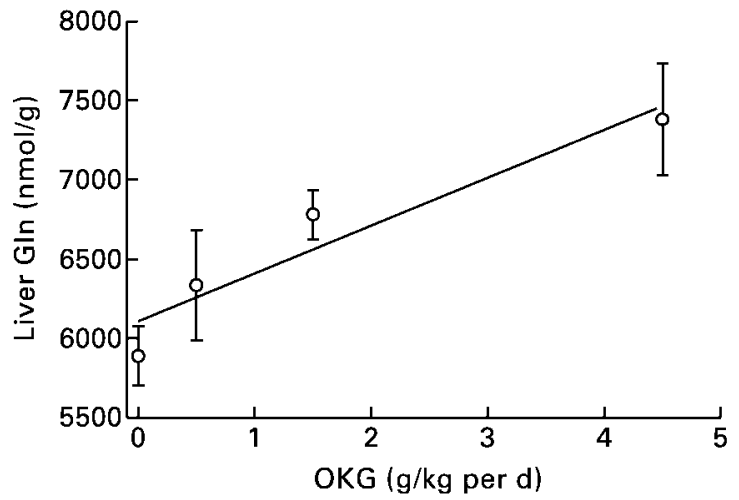

(B)

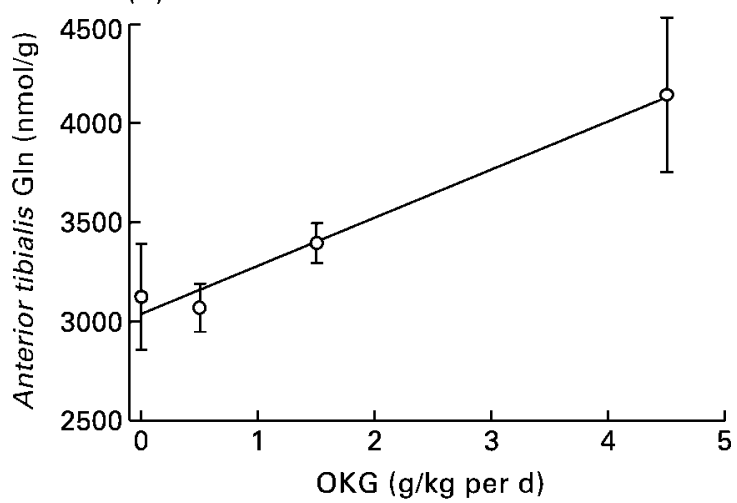

(D)

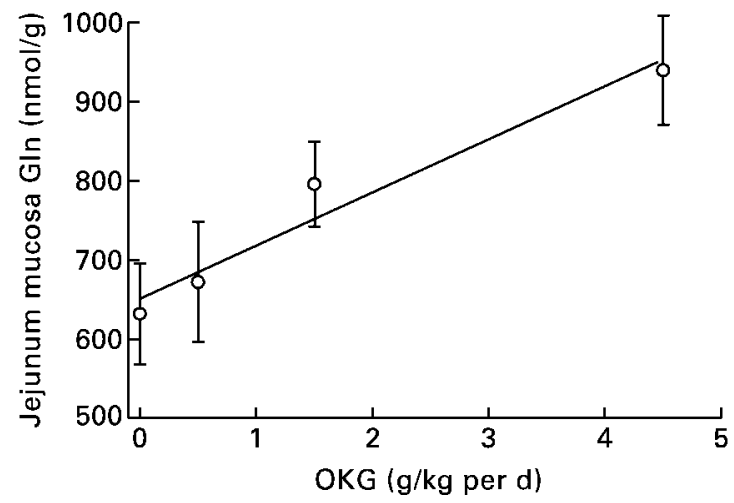

Fig. 3. Linear regression of $\alpha$-ketoglutarate (OKG) dose $v$. glutamine (GIn) concentrations in plasma (A), muscle (B), liver (C) and jejunum mucosa (D) in endotoxaemic rats at killing. For details of diets and procedures, see Table 1 and pp. 628-629. Values are means with their standard errors shown by vertical bars. (A), $y=46 x+786, r 0.99, P<0.01 ;(B), y=242 x+3041, r 0.98, P<0.05 ;(C), y=302 x+6107, r$ 0.95, $P<0.05$; (D) $y=67 x+651, r 0.97, P<0.05$; Spearman test.

Table 3. Plasma and tissue ornithine concentrations at killing ${ }^{\star} \dagger$

(Mean values with their standard errors)

\begin{tabular}{|c|c|c|c|c|c|c|c|c|c|c|}
\hline Group... & Mean & SEM & Mean & SEM & Mean & SEM & Mean & SEM & Mean & SEM \\
\hline Jejunum mucosa (nmol/g) & $79^{a}$ & 5 & $84^{a}$ & 7 & $77^{\mathrm{a}}$ & 5 & $87^{a}$ & 8 & $161^{b}$ & 27 \\
\hline Liver $(\mathrm{nmol} / \mathrm{g})$ & $236^{a}$ & 8 & $241^{\mathrm{a}}$ & 9 & $234^{a}$ & 8 & $236^{\mathrm{a}}$ & 4 & $311^{\mathrm{b}}$ & 22 \\
\hline Anterior tibialis $(\mathrm{nmol} / \mathrm{g})$ & $47^{\mathrm{a}}$ & 4 & $59^{a}$ & 6 & $58^{\mathrm{a}}$ & 4 & $78^{a}$ & 9 & $516^{b}$ & 106 \\
\hline
\end{tabular}

LPS, lipopolysaccharide; OKG, Ornithine $\alpha$-ketoglutarate.

${ }_{\mathrm{a}, \mathrm{b}}$ Mean values within a row with unlike superscript letters were significantly different $(P<0.05)$.

${ }^{*}$ For details of groups and procedures, see Table 1 and pp. 628-629.

†For each variable, when an overall significant difference among the five groups was found (one-way ANOVA), the Newman-Keuls post hoc

test was performed.

(Vaubourdolle et al. 1991; Kalfarentzos et al. 1996; Le Boucher et al. 1997a), with various intermediate dosages. However, there was no real rationale for the doses used. Accordingly, to determine the optimal dose, we performed 'dose-ranging' with a progression common ratio of 3 , from 0.5 to $4.5 \mathrm{~g} / \mathrm{kg}$ per d, to cover the full range of doses of OKG reported in the literature. We administered OKG as boluses because it has been shown that for a given dose, boluses are more efficient than continuous intragastric administration, especially for biological markers of protein turnover and wound healing (Le Bricon et al. 1997;
De Bandt et al. 1998). In addition, as OKG is a Gln precursor (Cynober, 2004), the use of boluses was considered relevant since a high dose of Gln as a bolus gives protection from endotoxaemic shock in rats (Wischmeyer et al. 2001). In addition, fractionation of the OKG dose in boluses permits high dosages without increasing side-effects such as diarrhoea (De Bandt et al. 1998).

The metabolic effects of OKG are linked to the metabolites released in vivo from Orn and $\alpha$-ketoglutarate (Le Boucher \& Cynober, 1998). OKG acts in two major metabolic cycles: the Krebs cycle with its $\alpha$-ketoglutarate 
Table 4. Plasma and tissue proline concentrations at killing ${ }^{*} \dagger$

(Mean values with their standard errors)

\begin{tabular}{|c|c|c|c|c|c|c|c|c|c|c|}
\hline \multirow{2}{*}{ Group... } & \multicolumn{2}{|c|}{ Control } & \multicolumn{2}{|c|}{ LPS-OKG-0.0 } & \multicolumn{2}{|c|}{ LPS-OKG-0.5 } & \multicolumn{2}{|c|}{ LPS-OKG-1.5 } & \multicolumn{2}{|c|}{ LPS-OKG-4.5 } \\
\hline & Mean & SEM & Mean & SEM & Mean & SEM & Mean & SEM & Mean & SEM \\
\hline Plasma $(\mu \mathrm{mol} / \mathrm{l})$ & $162^{\mathrm{a}}$ & 7 & $182^{\mathrm{a}}$ & 13 & $186^{\mathrm{a}}$ & 7 & $199^{a}$ & 10 & $320^{\mathrm{b}}$ & 25 \\
\hline Jejunum mucosa $(\mathrm{nmol} / \mathrm{g})$ & 599 & 50 & 646 & 55 & 666 & 49 & 769 & 60 & 662 & 67 \\
\hline Liver $(\mathrm{nmol} / \mathrm{g})$ & $144^{\mathrm{a}}$ & 6 & $223^{\mathrm{bc}}$ & 15 & $215^{\mathrm{bc}}$ & 12 & $187^{\mathrm{b}}$ & 10 & $232^{c}$ & 15 \\
\hline Anterior tibialis $(\mathrm{nmol} / \mathrm{g})$ & $241^{a}$ & 12 & $293^{\mathrm{b}}$ & 17 & $305^{\mathrm{b}}$ & 11 & $342^{\mathrm{b}}$ & 24 & $628^{\mathrm{C}}$ & 51 \\
\hline
\end{tabular}

LPS, lipopolysaccharide; OKG, ornithine $\alpha$-ketoglutarate.

a,b,c Mean values within a row with unlike superscript letters were significantly different $(P<0.05)$

* For details of groups and procedures, see Table 1 and pp. 628-629.

†For each variable, when an overall significant difference among the five groups was found (one-way ANOVA), the Newman-Keuls post hoc test was performed.

Table 5. Plasma and tissue arginine concentrations at killing* ${ }^{*}$ (Mean values with their standard errors)

\begin{tabular}{|c|c|c|c|c|c|c|c|c|c|c|}
\hline \multirow{2}{*}{ Group... } & \multicolumn{2}{|c|}{ Control } & \multicolumn{2}{|c|}{ LPS-OKG-0.0 } & \multicolumn{2}{|c|}{ LPS-OKG-0.5 } & \multicolumn{2}{|c|}{ LPS-OKG-1.5 } & \multicolumn{2}{|c|}{ LPS-OKG-4.5 } \\
\hline & Mean & $\overline{\text { SEM }}$ & Mean & $\overline{\text { SEM }}$ & Mean & SEM & Mean & SEM & Mean & SEM \\
\hline Plasma $(\mu \mathrm{mol} / \mathrm{l})$ & 115 & 8 & 96 & 6 & 96 & 6 & 99 & 6 & 105 & 6 \\
\hline Jejunum mucosa $(\mathrm{nmol} / \mathrm{g})$ & 220 & 30 & 183 & 15 & 198 & 24 & 229 & 25 & 193 & 28 \\
\hline Anterior tibialis $(\mathrm{nmol} / \mathrm{g})$ & $153^{\mathrm{a}}$ & 12 & $113^{b}$ & 15 & $94^{\mathrm{b}}$ & 6 & $89^{b}$ & 8 & $143^{\mathrm{a}}$ & 15 \\
\hline
\end{tabular}

LPS, lipopolysaccharide; OKG, ornithine $\alpha$-ketoglutarate.

a,b Mean values within a row with unlike superscript letters were significantly different $(P<0.05)$.

${ }^{*}$ For details of groups and procedures, see Table 1 and pp. 628-629.

†For each variable, when an overall significant difference among the five groups was found (one-way ANOVA), the Newman-Keuls post hoc test was performed.

moiety and the urea cycle with its Orn moiety. OKG metabolites include Gln, Arg and Pro derived from Orn metabolism and OKG stimulates hormone (insulin and human growth hormone) secretion (Cynober et al. 1984; Cynober, 1991).

Our present 'dose-ranging' study clearly shows a linear relationship between dose of OKG administered and Gln, Orn and Pro tissue repletion. OKG is able to enhance Gln pools linearly in all tissues, confirming the major role of OKG as a Gln precursor and/or as sparing endogenous Gln stores (Le Boucher \& Cynober, 1998). Our present results add to those observed in malnourished rats, showing a dose-related effect on Gln concentrations in plasma and muscle (Ziegler et al. 1991).

It is noteworthy that although OKG provides Orn directly, only the highest dose induced a significantly increased concentration in all tissues compared with controls. This may be related to the fact that Orn is heavily used in gluconeogenesis, a pathway that is activated in the present stress model. Thus, only $4.5 \mathrm{~g}$ OKG/ $\mathrm{kg}$ per $\mathrm{d}$ was able to increase both Gln and Orn concentrations in jejunum mucosa; these substances act as an enterocyte fuel and purine precursor, and as a polyamine precursor respectively. We did not study intestinal function, but this observation is in line with results obtained in different experimental models showing that OKG can improve intestinal trophicity and brush border enzyme content (Duranton et al. 1998) or stimulate villi hyperplasia after intestinal resection (Dumas et al. 1998).

Pro, which is involved in tissue repair (Young \& El-Khouri, 1995), showed variations that were also linearly linked to OKG dose in plasma, muscle and liver at the highest dose. The action of Pro in collagen synthesis, a key step in wound healing, has been involved in OKG beneficial effects after burns (Le Bricon et al. 1997). Arg, which is an OKG metabolite mainly via Orn metabolism in ureagenesis, has been shown to increase in several tissues in endotoxaemic (Lasnier et al. 1996) and burned (Roch-Arveiller et al. 1996) rats treated with OKG. This increase was also found in our present study, restricted to muscle. This confirms that although OKG leads to Arg production in vivo, its main property is to act as a Gln precursor.

Important properties of OKG are improvement of $\mathrm{N}$ balance (Le Bricon et al. 1995; De Bandt et al. 1998; Donati et al. 1999) and reduction of myofibrillar catabolism (Le Boucher et al. 1997b; De Bandt et al. 1998; CoudrayLucas et al. 2000). N balances were negative from day 0 to day 1 in the control and LPS groups because of the fasting state, but, as expected, were more negative in the endotoxaemic group. After injury, we found a positive linear relationship between OKG dose and cumulative $\mathrm{N}$ balance. However, only the highest dose allowed a positive mean value, whereas other OKG-treated groups and controls had a mean cumulative $\mathrm{N}$ balance not different from equilibrium, i.e. null. Of course, it is hopeless to obtain a positive $\mathrm{N}$ balance in stressed patients during the 'flow phase'. However, it has been shown that pharmaconutrients can limit $\mathrm{N}$ loss in stressed patients; since the rat is more sensitive than humans to nutritional manipulation, the results we obtained highlight the ability of OKG to modulate protein metabolism. Likewise, a beneficial effect of $\mathrm{OKG}$ on myofibrillar catabolism was only observed with 
the highest dose in the LPS-OKG-4.5 group, which was not different from the control group for urinary 3-methylhistidine excretion. We can hypothesize that the lack of correlation between OKG dose and 3-methylhistidine excretion may show that muscle Gln replenishment is required to obtain an OKG effect on myofibrillar catabolism, since the LPS-OKG-4.5 group was the only one that maintained muscle Gln concentration.

In conclusion, in this experimental model we found beneficial effects exerted by $\mathrm{OKG}$ in the context of injury and a dose-related effect on tissue Gln concentrations and $\mathrm{N}$ balance. This 'dose-ranging' study is new and provides data on $\mathrm{OKG}$ metabolite generation at the tissular level that cannot be obtained in human subjects for obvious ethical reasons, and which confirm the major role of $\mathrm{OKG}$ in generating Gln in tissues. Given that only the highest dose of $4.5 \mathrm{~g} / \mathrm{kg}$ per d was able to counteract the myofibrillar catabolism, achieve positive $\mathrm{N}$ balance, restore Gln pools and increase tissue Orn, Pro and Arg concentrations, we recommend a daily dose of $\mathrm{OKG}$ in this range for further animal studies designed to elucidate the mechanisms of action of OKG.

\section{Acknowledgements}

This study was supported in part by Chiesi SA. P. P. was a recipient of an ESPEN research fellowship.

\section{References}

Blondé-Cynober F, Aussel C \& Cynober L (2003) Use of ornithine $\alpha$-ketoglutarate in clinical nutrition of elderly patients. Nutrition 19, 73-75.

Cardenas D, Le Bricon T \& Cynober L (2002) L'alpha-cétoglutarate d'ornithine: mécanismes d'action et place actuelle en nutrition artificielle (Ornithine $\alpha$-ketoglutarate: mechanisms of action and role in clinical nutrition). Nutr Clin Metabol 16, $151-163$.

Chambon-Savanovitch C, Felgines C, Farges MC, Raul F, Cezard JP, Davot P, Vasson MP \& Cynober LA (1999) Comparative study of glycine, alanine or casein as inert nitrogen sources in endotoxemic rats. J Nutr 129, 1866-1870.

Coudray-Lucas C, Le Bever H, Cynober L, De Bandt JP \& Carsin H (2000) Ornithine $\alpha$-ketoglutarate improves wound healing in severe burn patients. A prospective randomized double-blind trial versus isonitrogenous controls. Crit Care Med 28, 1772-1776.

Cynober L (1991) Ornithine $\alpha$-ketoglutarate in nutritional support. Nutrition 7, 313-321.

Cynober L (1995) Place des nouveaux substrats azotés en nutrition artificielle périopératoire de l'adulte (New nitrogen substrates in perioperative artificial nutrition). Nutr Clin Metabol 9, $113-117$

Cynober L (2004) Ornithine $\alpha$-ketoglutarate. In Metabolic and Therapeutic Aspects of Amino Acids in Clinical Nutrition, pp. 633-648 [LA Cynober, editor]. Boca Raton, FL: CRC Press.

Cynober LA (1999) The use of $\alpha$-ketoglutarate salts in clinical nutrition and metabolic care. Curr Opin Clin Nutr Metab Care 2, 33-37.

Cynober L, Coudray-Lucas C, De Bandt JP, Guechot J, Aussel C, Salvucci M \& Giboudeau J (1990) Action of ornithine $\alpha$-ketoglutarate, ornithine hydrochloride, and calcium $\alpha$-ketoglutarate on plasma amino acids and hormonal patterns in healthy subjects. J Am Coll Nutr 9, 2-12.

Cynober L, Vaubourdolle M, Dore A \& Giboudeau J (1984) Kinetics and metabolic effects of orally administered ornithine alpha-ketoglutarate in healthy subjects fed with a standardized regimen. Am J Clin Nutr 39, 514-519.

De Bandt JP, Coudray-lucas C, Lioret N, Lim SK, Saizy R, Giboudeau J \& Cynober L (1998) A randomized controlled trial of the influence of the mode of enteral ornithine $\alpha$-ketoglutarate administration in burn patients. J Nutr 128, 563-569.

De Bandt JP \& Cynober L (1998) Amino acids with anabolic properties. Curr Opin Clin Nutr Metab Care 1, 263-272.

Donati L, Ziegler F, Pongelli G \& Signorini MS (1999) Nutritional and clinical efficacy of ornithine alpha-ketoglutarate in severe burn patients. Clin Nutr 18, 307-311.

Dumas F, De Bandt JP, Colomb V, Le Boucher J, Coudray-Lucas C, Lavie S, Brousse N, Ricour C, Cynober L \& Goulet O (1998) Enteral ornithine alpha-ketoglutarate enhances intestinal adaptation to massive resection in rats. Metabolism 47, 1366-1371.

Duranton B, Schleiffer R, Gossé F \& Raul F (1998) Preventive administration of ornithine alpha-ketoglutarate improves intestinal mucosal repair after transient ischemia in rats. Crit Care Med 26, 120-125.

Fink M \& Heard SO (1990) Laboratory models of sepsis and septic shock. J Surg Res 49, 186-196.

Hall JC (1998) Glycine. J Parenter Enteral Nutr 22, 393-398.

Jeevanandam M, Holaday NJ \& Ali MR (1992) Altered tissue polyamine levels due to ornithine-alpha-ketoglutarate in traumatized growing rats. Metabolism 41, 1204-1209.

Kalfarentzos F, Spilioti J, Melachrinou M, Katsarou CH, Spiliopoulou I, Panagopoulos C \& Alexandrides TH (1996) Oral ornithine $\alpha$-ketoglutarate accelerates healing of the small intestine and reduces bacterial translocation after abdominal radiation. Clin Nutr 15, 29-33.

Lasnier E, Coudray-Lucas C, Le Boucher J, Jardel A \& Cynober L (1996) Ornithine alpha-ketoglutarate counteracts thymus involution and glutamine depletion in endotoxemic rats. Clin Nutr 15, 197-200.

Le Boucher J, Coudray-Lucas C, Lasnier E, Jardel A, Ekindjian OG \& Cynober L (1997a) Enteral administration of ornithine $\alpha$-ketoglutarate or arginine $\alpha$-ketoglutarate: a comparative study of their effects on glutamine pools in burn-injured rats. Crit Care Med 25, 293-298.

Le Boucher J \& Cynober LA (1998) Ornithine $\alpha$-ketoglutarate: the puzzle. Nutrition 14, 870-873.

Le Boucher J, Obled C, Farges MC \& Cynober L (1997b) Ornithine alpha-ketoglutarate modulates tissue protein metabolism in burn-injured rats. Am J Physiol 273, E557-E563.

Le Bricon T, Cynober L \& Baracos V (1994) Ornithine $\alpha$-ketoglutarate limits muscle protein breakdown without stimulating tumor growth in rats bearing Yoshida ascites hepatoma. Metabolism 7, 1-5.

Le Bricon T, Coudray-Lucas C, Lioret N, Lim SK, Plassart F, Schlegel L, De Bandt JP, Saizy R, Giboudeau J \& Cynober L (1997) Ornithine $\alpha$-ketoglutarate metabolism after enteral administration in burn patients: bolus compared with continuous infusion. Am J Clin Nutr 65, 512-518.

Le Bricon T, Cynober L, Field CJ \& Baracos VE (1995) Supplemental nutrition with ornithine alpha-ketoglutarate in rats with cancer-associated cachexia: surgical treatment of the tumor improves efficacy of nutritional support. J Nutr 125, 2999-3010.

Moinard C, Caldefie F, Walrand S, Tridon A, Chassagne J, Vasson MP \& Cynober L (2002) Effects of ornithine 2-oxoglutarate on neutrophils in stressed rats: evidence for the involvement of nitric oxide and polyamines. Clin Sci 102, 287-295. 
Pernet P, Coudray-Lucas C, Le Boucher J, Schlegel L, Giboudeau J, Cynober L \& Aussel C (1999) Is the L-arginine:nitric oxide pathway involved in endotoxemia-induced muscular hypercatabolism in rats? Metabolism 48, 190-193.

Robinson LE, Bussière FI, Le Boucher J, Farges MC, Cynober LA, Field CJ \& Baracos VE (1999) Amino acid nutrition and immune function in tumour-bearing rats: a comparison of glutamine-, arginine- and ornithine 2-oxoglutarate-supplemented diets. Clin Sci 97, 657-669.

Roch-Arveiller M, Tissot M, Coudray-Lucas C, Fontagne J, Le Boucher J, Giroud JP \& Cynober L (1996) Immunomodulatory effects of ornithine $\alpha$-ketoglutarate in rats with burn injuries. Arch Surg 131, 718-723.

Vaubourdolle M, Coudray-Lucas C, Jardel A, Ziegler F, Ekindjian OG \& Cynober L (1991) Action of enterally administered ornithine alpha-ketoglutarate on protein breakdown in skeletal muscle and liver of the burned rat. $J$ Parenter Enteral Nutr 15, 517-520.

Wischmeyer PE, Kahana M, Wolfson R, Ren H, Musch MM \& Chang EB (2001) Glutamine induces heat shock protein and protects against endotoxin shock in the rat. $J$ Appl Physiol 90, 2403-2410.

Young VR \& El-Khouri A (1995) The notion of the nutritional essentiality of amino acids, revisited, with a note on the indispensable amino acid requirements in adults. In Amino Acid Metabolism and Therapy in Health and Nutritional Disease, pp. 191-232 [LA Cynober, editor]. Boca Raton, FL: CRC Press.

Ziegler F, Coudray-Lucas C, Jardel A, Lasnier E, Ekindjian OG \& Cynober L (1991) Dose-related effect of ornithine alphaketoglutarate on glutamine pools in vivo. Clin Nutr 10, Suppl. 2 (abstract). 